ORIGINAL ARTICLE

\title{
DD Genotype and Atherosclerosis in Overweight Menopausal Women
}

\author{
José Ramón Lanz-Luces, ${ }^{1,2}$ Fernando Alves Costa, 2,3@ Luis Fernando Escobar Guzman, ${ }^{1,3}$ Antonio Ricardo de \\ Toledo Gagliardi, ${ }^{\circledR}$ José Antonio Lanz-Luces, ${ }^{2}{ }^{\circledR}$ José Daniel Lanz-Souquett, ${ }^{2}{ }^{\circledR}$ Leandro Menezes Alves da Costa ${ }^{2,4}$ \\ Universidade de São Paulo - Instituto do Coração, ' São Paulo, SP - Brazil \\ Instituto Paulista de Doenças Cardiovasculares (IPDC), ${ }^{2}$ São Paulo, SP - Brazil \\ Hospital Beneficência Portuguesa de São Paulo, ${ }^{3}$ São Paulo, SP - Brazil \\ Hospital Alemão Oswaldo Cruz, ${ }^{4}$ São Paulo, SP - Brazil
}

\section{Abstract}

Background: Sex-specific pathology of coronary artery disease (CAD) has not been recognized. Women with obstructive or nonobstructive CAD associated with traditional risk factors have similar events; no studies have explored both populations in association with genetic markers.

Objective: To evaluate the DD genotype in overweight menopausal women and its association with CAD and traditional risk factors.

Method: This cross-sectional study included 356 menopausal women who underwent coronary angiography as CAD assessment. The patients' DNA was extracted and polymorphisms were detected with a single polymerase chain reaction assay. Two groups were formed based on luminal lesions (normal [ $n=134]$ or pathological [n=222]) with a cutoff value $>30 \%$, considering overweight and age. The chi-square test, Student's t-test, and multivariate logistic regression were performed as appropriate $(\mathrm{p}<0.05)$ using the following variables: overweight, diabetes, hypertension, dyslipidemia, smoking status, sedentary lifestyle, and a family history of CAD.

Results: The mean age of the sample was $63 \pm 8$ years, and the mean BMI was $28 \pm 5 \mathrm{~kg} / \mathrm{m}^{2}$. The DD genotype was slightly more prevalent in the pathological group $(30.2 \%$ vs. $21.6 \%, p=0.079)$, but this significantly changed when $\mathrm{BMI}>25$ was considered ( $33 \%$ vs. $18 \%, \mathrm{p}=0.012)$. In multivariate analysis with two threshold levels $(>50$ and $>60$ years), diabetes was significantly associated with CAD in both models ( $p=0.021 \mathrm{vs.} 0.009)$ but the genotype was only associated with younger age $(\mathrm{p}=0.034)$.

Conclusion: These data support an association between atherosclerosis and the renin-angiotensin system in overweight menopausal women that is dependent on the age at which the ischemic event occurs.

Keywords: Overweight; Menopause; Coronary Artery Disease; Genetic Markers; DD Genotype.

\section{Introduction}

Menopause, a unique physiological stage that occurs in middle-aged women, involves important metabolic changes. One of these changes is an increase in low-density lipoprotein levels, which is sometimes associated with age at menopause onset. ${ }^{1}$ In addition, lipid profile changes are strongly associated with coronary artery disease (CAD) in these women. This alteration has sometimes been attributed to the effects of hormone replacement on lowdensity lipoprotein particles. ${ }^{2}$ Studies have emphasized that although estrogen therapy increases the levels of high-density lipoprotein and its components, ${ }^{4}$ individual variability, which depends on allelic variants of the estrogen receptor gene, is also a factor. ${ }^{3}$ A publication

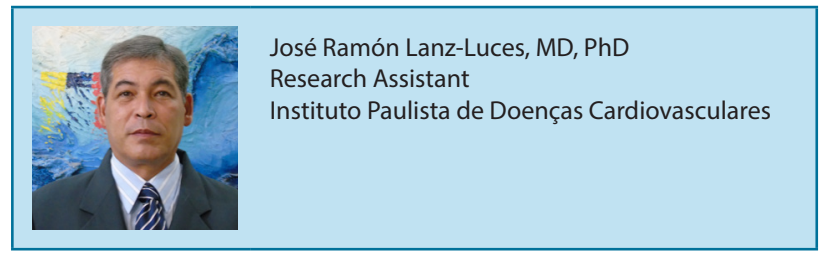


by the Women's Health Group recommends limiting hormone replacement therapy in menopausal women due to the higher relative risk of CAD in a population that already had a high rate of CAD prior to enrolment. ${ }^{5}$

Recent studies have also investigated the role of adipose tissue, specifically its molecular mediators (eg, adipocytokines) in menopausal women. ${ }^{6}$ Of note, obesity is common in menopausal women and increases inflammatory cytokine levels, integrating metabolic and inflammatory responses. ${ }^{7}$ One of these concepts is derived from an observed association between the blockade of AT1 receptors and adiponectin expression. ${ }^{8}$ Low levels of adiponectin are associated with higher levels of interleukin- $6,{ }^{9}$ a molecule that is involved in atherosclerosis. ${ }^{10}$ In addition, AT1 receptors in circulating macrophages play a role in angiotensin II-mediated cytokine production. ${ }^{11}$

There is a 287-base pair insertion/deletion polymorphism in the angiotensin-converting enzyme gene in intron 16, resulting in three genotypes; II, ID and DD. The latter is a linkage marker with therapeutic implications in cardiovascular disease. ${ }^{12}$

Clinically, the DD genotype has already been associated with endothelial dysfunction in postmenopausal women, ${ }^{13}$ as well as with CAD. Amara et $\mathrm{al}^{14}{ }^{14}$ found a significant prevalence of the DD genotype in a population with symptomatic CAD (odds ratio $[\mathrm{OR}]=6.8,95 \%$ confidence interval [CI]: 4.4-10, $\mathrm{p}<0.001)$. The risk was greatly potentiated by several concomitant risk factors (smoking, diabetes, hypertension, dyslipidemia, and family history of CAD).
Considering this scenario, a better diagnostic method for classifying CAD risk is necessary. Based on existing evidence, the DD genotype increases the risk of CAD in younger individuals. ${ }^{15}$ Moreover, a metabolic transition threshold is observed during the menopausal age. ${ }^{16}$ We suggest that the polymorphism in this special condition, along with related factors, could be involved in atherosclerosis and can be evaluated using coronary angiography.

\section{Materials and Methods}

This was a retrospective, observational, analytic crosssectional cohort single-center study (at the Heart Institute, University of São Paulo). Participants were selected from a database of 1449 patients during 2001 to 2003, (only one investigator was present at upon patient arrival for coronary angiogram and his availability depended on institutional hours). The investigator was available approximately $70 \%$ of the time at the hemodynamic laboratory to perform the optional coronary angiogram for the patients. Thus, a mixed sample design was selected to produce a representative sample and to surpass the minimum required sample size, using purposeful random sampling (random cases were selected from the sampling frame, alternating morning and afternoon tests), criterion sampling (only patients with suspected or proven $\mathrm{CAD}$ ), and convenience sampling (in the chosen setting, groups and/or individuals who are conveniently available and willing to participate) as previously described..$^{17}$ From this database we selected 583 female patients, whose mean age was $63 \pm 8$ years (Table 1). The sample's clinical characteristics included the

Table 1 - Population characteristics

\begin{tabular}{|c|c|c|c|c|}
\hline & General (356) & Normal (134) & vs. Pathological (222) & p-value \\
\hline Age (years) & $63 \pm 8$ & $61 \pm 8$ & $65 \pm 8$ & $<0.001$ \\
\hline BMI $\left(\mathrm{Kg} / \mathrm{m}^{2}\right)$ & $28 \pm 5$ & $29 \pm 5.8$ & $27 \pm 4.9$ & 0.008 \\
\hline $\mathrm{DM}$ & $128(36 \%)$ & $34(26.6 \%)$ & $94(73.4 \%)$ & 0.001 \\
\hline HT & $288(81 \%)$ & $102(35.4 \%)$ & $186(64.6 \%)$ & 0.075 \\
\hline DLP & $213(59.8 \%)$ & $76(35.7 \%)$ & $137(64.3 \%)$ & 0.352 \\
\hline SM & $87(24.4 \%)$ & $32(36.8 \%)$ & $55(63.2 \%)$ & 0.849 \\
\hline CAD hist. & $255(71.6 \%)$ & $96(37.6 \%)$ & $159(62.4 \%)$ & 0.997 \\
\hline DD genotype & $96(27 \%)$ & $29(30.2 \%)$ & $67(69.8 \%)$ & 0.079 \\
\hline
\end{tabular}


following variables: age, menopause (permanent cessation of ovulation) for at least 1 year.

Hypertension was defined as having been prescribed anti-hypertensive medications or blood pressure exceeding 140/90 mmHg. Diabetes was defined as hemoglobin a A1c value $>6.5 \%$ or fasting plasma glucose $\geq 126 \mathrm{mg} / \mathrm{dl}$ and/or the use of insulin or oral hypoglycemic agents. Dyslipidemia was defined according to laboratory results (total cholesterol $\geq 200 \mathrm{mg} / \mathrm{dl}$, low-density lipoprotein cholesterol $\geq 130$ $\mathrm{mg} / \mathrm{dl}$, high-density lipoprotein cholesterol $<40 \mathrm{mg} / \mathrm{dl}$, triglycerides $\geq 150 \mathrm{mg} / \mathrm{dl}$ and/or hypolipidemic agent use), sedentary lifestyle, and a first-degree family history of CAD (<65 years). Smoking was defined as daily or occasional selfreported cigarette consumption without having quit in the last year. Weight and height were assessed to determine body mass index (BMI), expressed as $\mathrm{kg} / \mathrm{m}^{2}$ (Table 1 ). A BMI $>25 \mathrm{Kg} / \mathrm{m}^{2}$ was considered overweight.

\section{Inclusion criteria}

All patients underwent coronary catheterization to determine the presence of $\mathrm{CAD}$, in addition to considering the presence of angina pectoris or the results of one of the following positive noninvasive tests: treadmill, echocardiogram with dobutamine, or cardiac scintigraphy. Some patients were asymptomatic, while others had adverse events such as unstable angina or myocardial infarction without previous coronary angiography. To be included, a patient had to provide all clinical data regarding the study variables (anthropometric measures and risk factors) and written informed consent prior to the coronary angiogram.

\section{Exclusion criteria}

Patients were excluded if they had previously undergone coronary angiography due to an ischemic event or if they were admitted to the hospital in an unstable condition.

\section{Genotyping}

An 8-mL peripheral blood sample was taken from each patient. The sample was stored in a tube containing ethylenediaminetetraacetic acid, and the DNA was obtained through the saline method. A polymerase chain reaction assay was performed to amplify the selected strain, using two primer kits for the insertion/ deletion polymorphism of the angiotensin-converting enzyme gene (including an intronic pair), as described elsewhere. This was considered a post-hoc analysis from a previous study. ${ }^{18}$

Twenty coronary segments were examined to determine the presence of atherosclerosis. Epicardial vessels or main branches were divided into three segments (proximal, medial, and distal), except for secondary branches of the right coronary artery, which were divided into proximal and distal portions; this special classification was part of a previous study. ${ }^{18}$ Patients were divided into two groups: those with and without lesions (ie, normal vs. pathological angiogram). A cutoff value of $>30 \%$ obstruction was established. The coronary angiogram threshold was considered non-significant from the point of view of obstructive angiography, but it established the presence of atherosclerosis. This cutoff value was derived from the Assessing Angiography Project as a lower range in visual assessment. ${ }^{19}$ We also divided the population into groups according to $\mathrm{BMI}>$ or $<25$ $\mathrm{kg} / \mathrm{m}^{2}$ and the presence or absence of CAD.

For logistic analysis, age was dichotomized as $>50$ years or $>60$ years, since: (1) studies have reported that the mean age of menopause onset ranges from 49-52 years, ${ }^{20}$ and (2) the World Health Organization describes those aged $\geq 60$ years as older adults.

This study was approved by the institutional ethics and research committee and was conducted in accordance with the most recent Declaration of Helsinki and World Medical Association guidelines. All patients provided written informed consent prior to participation. The study protocol did not interfere with any medical treatment and/or recommendations or other institutional protocols.

\section{Statistical analyses}

The sample size was calculated considering two groups for regression analysis and a power of 95\%. A minimum of 119 patients were required for each group and a total of 234 cases. We used the KolmogorovSmirnov test to assess data normality. Continuous variables were expressed as means and standard deviations and categorical variables as absolute values and percentages. To assess the difference between the groups, we used the chi-square test to determine the frequency of the angiotensin-converting enzyme genotype and alleles and to determine the association between gene polymorphisms and normal and pathological angiograms. The chi-square test 
was also used to compare the proportions of classic cardiovascular risk factors between the groups. An unpaired $t$-test was used to determine the differences in continuous variables between the groups at baseline. The OR of a pathological coronary angiogram was determined using dichotomized risk factors, including the DD genotype, as independent predictors. Multivariate logistic regression analysis was performed in three different settings (the whole population and for two age ranges, $>50$ and 60 years). P-values $<0.05$ were considered significant. All tests were two-tailed. The data were analyzed using SPSS version 23 (SPSS, Chicago Illinois) and G*Power version 3.1.9.7 (Heinrich Heine University, Düsseldorf, Germany).

\section{Results}

Ninety-five patients were excluded due to previous bypass surgery or angioplasty, and another 129 were excluded because they were non-menopausal at enrolment. As a result, 356 patients were included in the study (Figure 1). The mean age of those in the pathological groups was significantly older but they had lower BMI values (Table 1). In both groups, non-significant associations were found between a pathological angiogram and hypertension, dyslipidemia, smoking, a family history of $\mathrm{CAD}$, and the $\mathrm{DD}$ genotype.
However, a pathological angiogram was also associated with older age, diabetes, and BMI (Table 1).

\section{Frequency of alleles and genotypes}

The relative frequencies of II, ID, and DD genotypes were $21.3 \%, 50.4 \%$, and $28.3 \%$, respectively. The allele frequencies were $46.5 \%$ and $53.5 \%$ for inserted and deleted alleles, respectively. These results were consistent with the Hardy-Weinberg equilibrium.

\section{Body mass index and DD genotype}

There was a high prevalence of overweight patients (BMI $\left.>25 \mathrm{~kg} / \mathrm{m}^{2}\right)$ in this population $(\mathrm{n}=244,68.5 \%)$, and $61.5 \%$ had a pathological angiogram $(\mathrm{n}=150)$. Similarly, $64.3 \%$ of patients in the BMI $\leq 25 \mathrm{~kg} / \mathrm{m}^{2}$ group had a pathological angiogram, which was a non-significant difference $(p=0.611)$. There was a higher prevalence of the DD genotype in the pathological group (30.2\%) than the normal group (21.6\%), but this was also nonsignificant (Figure 2). However, among menopausal with with a BMI $>25 \mathrm{~kg} / \mathrm{m}^{2}$, DD genotype frequency was significantly higher in the pathological group (34\%) than the normal group (19.1\%), (Figure 3).

Postmenopausal cardiovascular disease has two changing factors regarding the DD genotype. First,

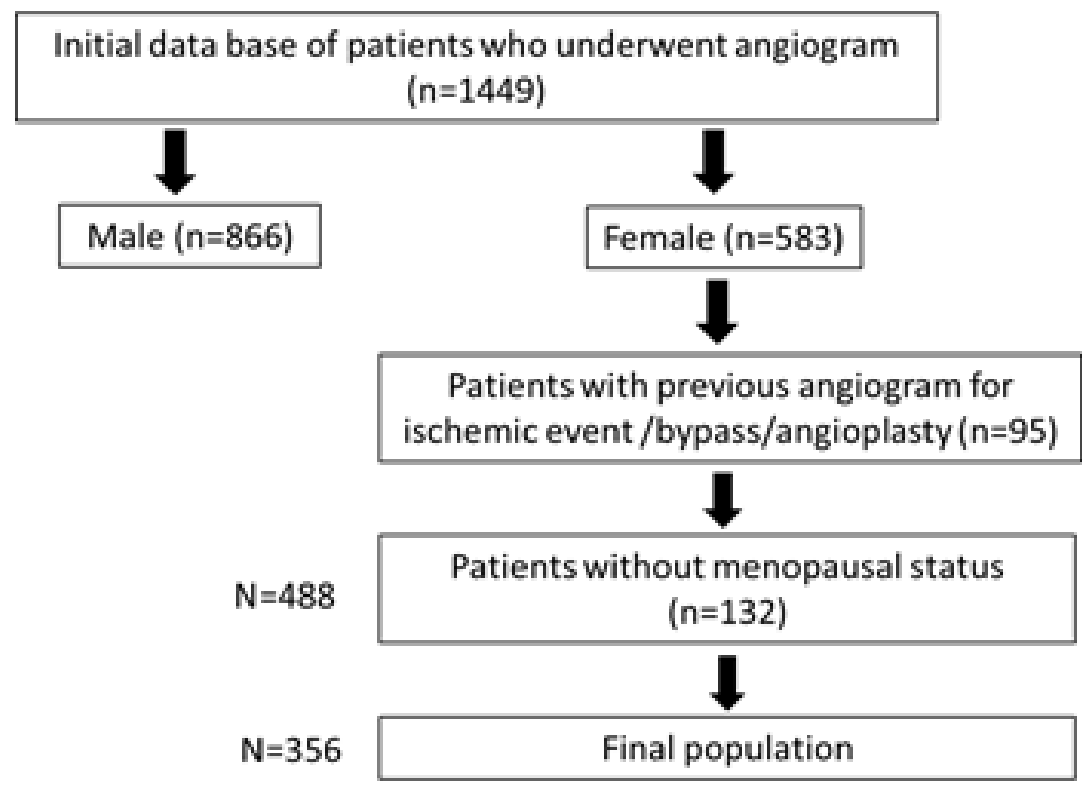

Figure 1 - Flow diagram of the study population 


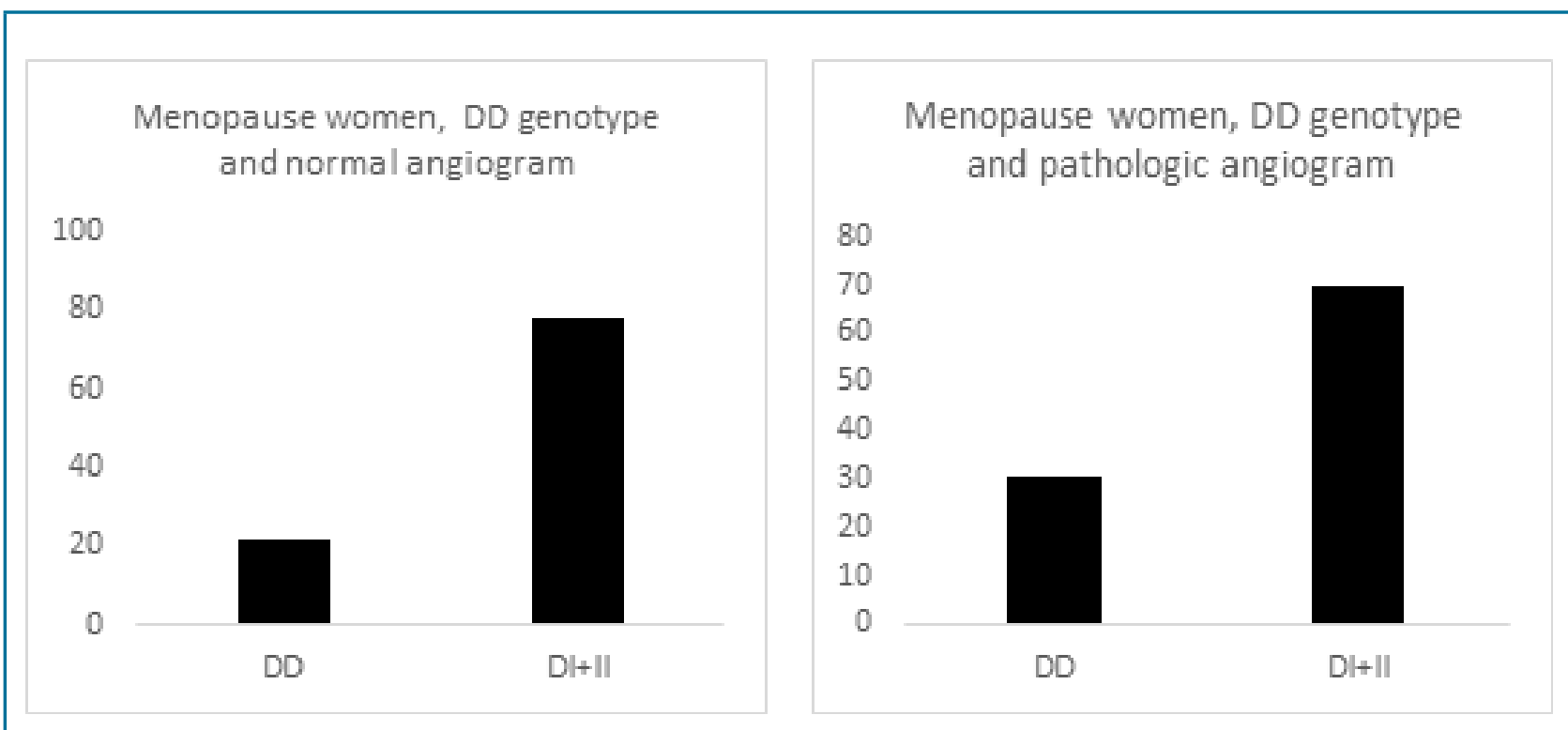

Figure 2 - DD genotype and angiogram status in menopausal women. Values expressed as percentages, $\mathrm{p}=0.079$
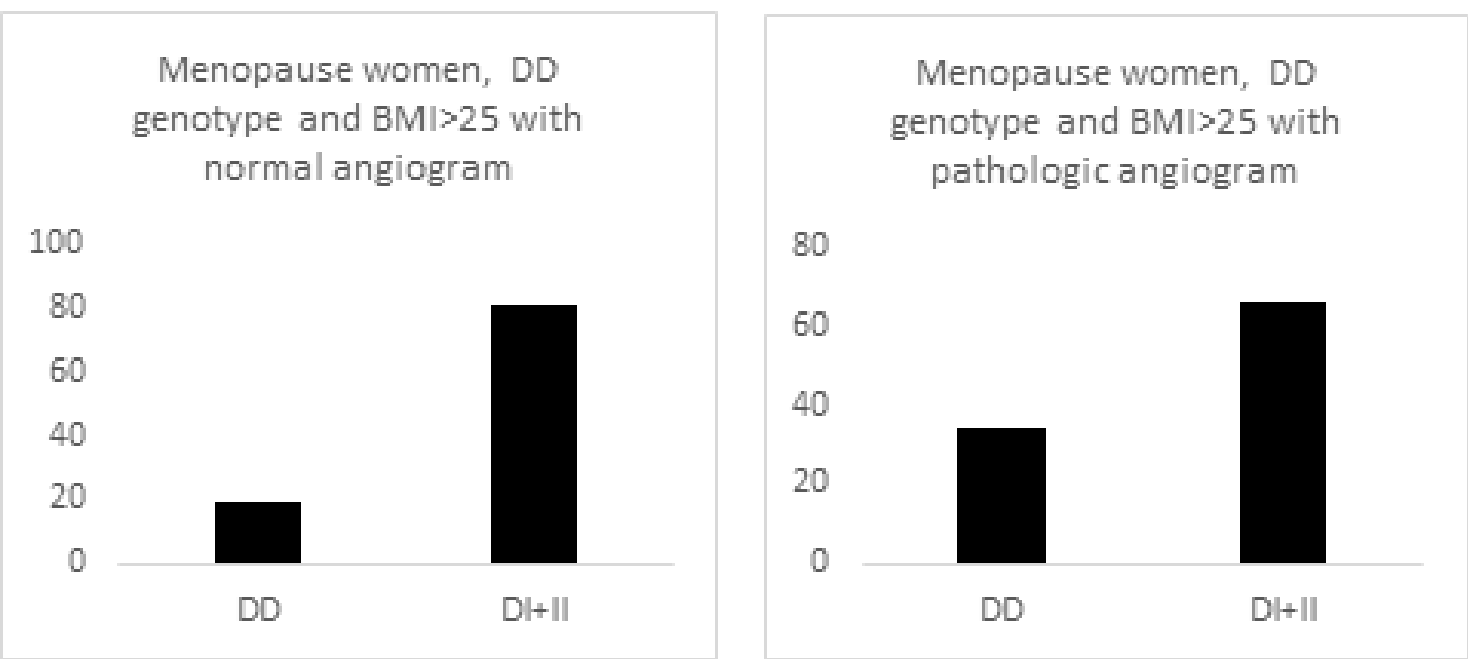

Figure 3 - DD genotype and angiogram status in menopausal women with BMI $>25$. Values expressed as percentages, $\mathrm{p}=0.012$

according to univariate analysis, there was an association between a pathological angiogram and age $(p<0.001)$, diabetes $(p=0.009)$, and DD genotype $(p=0.012)$ in postmenopausal women with a BMI $>25 \mathrm{~kg} / \mathrm{m}^{2}$. The remaining variables were not associated with pathology, although they were included in the logistic model (Table 2). In overweight women, diabetes was associated with pathology in both age ranges, but the DD genotype was only associated with the younger age range (Table 2). For women with a lower BMI, pathology was associated with age, diabetes, and hypertension. In a multivariate analysis, only age was significant $(p=0.037)$ (data not shown).

Age was significantly associated with coronary lesions in the overall population, but when divided by age, the association was not observed in the younger group ( $>$ 50 years, $\mathrm{p}=0.345 ;>60$ years, $\mathrm{p}=0.057$ ). However, age 
Table 2 - The relationship between angiogram lesion and cardiovascular risk factors in menopausal overweight women

\begin{tabular}{|c|c|c|c|c|c|c|c|}
\hline \multirow{2}{*}{ * } & \multirow{2}{*}{ B } & \multirow{2}{*}{ SD } & \multirow{2}{*}{ Wald } & \multirow{2}{*}{ p-value } & \multirow{2}{*}{$\operatorname{Exp}(B)$} & \multicolumn{2}{|c|}{$95 \% \mathrm{CI}$} \\
\hline & & & & & & Inferior & Superior \\
\hline M50 & 0.526 & 0.489 & 1.157 & 0.282 & 1.692 & 0.649 & 4.410 \\
\hline DM & 0.666 & 0.288 & 5.358 & 0.021 & 1.946 & 1.107 & 3.418 \\
\hline HT & 0.023 & 0.380 & 0.004 & 0.951 & 1.023 & 0.486 & 2.156 \\
\hline DLP & 0.139 & 0.283 & 0.240 & 0.624 & 1.149 & 0.660 & 2.001 \\
\hline SM & -0.187 & 0.338 & 0.308 & 0.579 & 0.829 & 0.428 & 1.607 \\
\hline Sedentary & -0.545 & 0.849 & 0.412 & 0.521 & 0.580 & 0.110 & 3.061 \\
\hline DD & 0.680 & 0.320 & 4.517 & 0.034 & 1.975 & 1.054 & 3.699 \\
\hline \multirow{2}{*}{ ** } & \multirow[b]{2}{*}{ B } & \multirow[b]{2}{*}{ SD } & \multirow[b]{2}{*}{ Wald } & \multirow{2}{*}{$\mathrm{p}$-value } & \multirow{2}{*}{$\operatorname{Exp}(B)$} & \multicolumn{2}{|c|}{$95 \% \mathrm{CI}$} \\
\hline & & & & & & Inferior & Superior \\
\hline M60 & 0.842 & 0.288 & 8.531 & 0.003 & 2.322 & 1.319 & 4.088 \\
\hline $\mathrm{DM}$ & 0.768 & 0.296 & 6.747 & 0.009 & 2.157 & 1.208 & 3.854 \\
\hline HT & -0.062 & 0.391 & 0.025 & 0.874 & 0.940 & 0.437 & 2.022 \\
\hline DLP & 0.148 & 0.287 & 0.265 & 0.607 & 1.159 & 0.660 & 2.035 \\
\hline $\mathrm{SM}$ & -0.118 & 0.344 & 0.118 & 0.731 & 0.888 & 0.453 & 1.742 \\
\hline Sedentary & -0.702 & 0.877 & 0.641 & 0.423 & 0.496 & 0.089 & 2.762 \\
\hline $\mathrm{DD}$ & 0.621 & 0.326 & 3.622 & 0.057 & 1.861 & 0.982 & 3.529 \\
\hline
\end{tabular}

was associated with pathology in older women when evaluating the overall population. Those $>60$ years had a higher risk of CAD (OR: 2.296, 95\% CI: 1.296-4.068) and diabetes (OR: 2.141, 95\% CI: 1.198-3.824).

There was a weak association between DD genotype and pathology in the overall population ( $p=0.071)$, as well as in women $>60$ years. However, there was a significant association between DD genotype and pathology in younger overweight patients. According to the regression analysis, there was a significant association between pathology, $\mathrm{BMI}<25$, and age $(\mathrm{p}=0.037)$ but not for the remaining variables, including the DD genotype and diabetes (data not shown).

In a complementary analysis in which the traditional cutoff value of $50 \%$ luminal obstruction was used to define a pathological angiogram, the prevalence was $68.6 \%$. Regression analysis revealed a significant association between diabetes and vessel obstruction in overweight women ( $p=0.002$ for $>50$ years and $p$ $=0.001$ for $>60$ years), but there were no significant associations with any of the other variables, including the DD genotype (data not shown).

\section{Discussion}

The pathways by which estrogen interacts with the cardiovascular system are not fully understood. Some experimental data on gene expression indicate that 17-B estradiol causes the downregulation of AT1 receptor mRNA. ${ }^{21}$ Other studies report that estrogen interferes with neointima formation, attenuating AT1 receptormediated activation of extracellular signal-regulated kinases and c-fos expression, thereby inhibiting vascular smooth muscle cell proliferation, an important step in atherosclerosis. ${ }^{22}$ 
Hypothetically, the more activated renin-angiotensin system in the DD genotype could be minimized with adequate estrogen levels until a follicular agedependent deficit is observed. At that time, hormoneassociated metabolic changes in the lipid profile promote the deposition of cholesterol, and there is a greater availability of low-density lipoprotein particles associated with angiotensin II throughout the LOX-1 receptor. ${ }^{23}$ Furthermore, in women on hormone replacement therapy, it has been shown that estrogen has lower levels of monocyte chemoattractant protein-1, which is involved in the progression of atherosclerosis by increasing both the number of macrophages and oxidized lipid accumulation in vessel walls. Other factors could also contribute to the risk of postmenopausal cardiovascular disease, one of which is obesity. In the current COVID-19 pandemic, the treatment and prevention of cardiovascular disease is receiving much attention, principally because it involves pathways that contribute to atherosclerosis. ${ }^{24}$ Obesity has also been associated with the polymorphism of angiotensin, and ethnic differences might affect this association. In a meta-analysis of 14 studies, the DD genotype was a risk factor for obesity. ${ }^{25}$ Differences were found between the DD and DI + II genotypes, at least among Africans, although three populations were evaluated (Asians, Caucasians, and Africans).

As expected, the authors of the review found an association between classic risk factors, hypertension, and diabetes in the univariate and multivariate analyses. In our multivariate analysis, the independent variables were age and diabetes; the latter was maintained in the three models only among patients with BMI $>25 \mathrm{~kg} / \mathrm{m}^{2}$.

Certain factors must be considered when determining atherosclerosis with a coronary angiogram. Mild luminal irregularities in angiography are associated with a higher disease burden and greater high-risk plaque density than when more accurate methods, such as intravascular ultrasound, are used. ${ }^{26}$ Furthermore, nonobstructive coronary artery disease is becoming more common in women, and its risk of major adverse events is similar to obstructive CAD. ${ }^{27}$ Thus, studying patients with obstructive lesions as well as those with lesser plaque obstruction is justifiable. Considering the disease as a continuum, it was important to compare patients with some degree of atherosclerotic lesion who required clinical or noninvasive assessment to diagnose coronary ischemia and to use a lower limit than the routine threshold of $50 \%$ in traditional angiography. ${ }^{28}$ Moreover, through vascular remodeling, plaque can frequently modulate the vascular bed without reducing vessel volume. ${ }^{29}$ Thus, atherosclerotic plaque could be underestimated in a routine coronary angiogram, and using the standard threshold of $50 \%$ could complicate the prediction of clinical outcomes.

Finally, apart from the expressive association between diabetes and $\mathrm{CAD},{ }^{30}$ the incidence of postmenopausal cardiovascular disease appears to be strongly associated with two independent factors when evaluating the DD genotype: younger age ( $>50$ years) at first ischemic event, followed by weight $\left(\mathrm{BMI}>25 \mathrm{~kg} / \mathrm{m}^{2}\right)$. Both of these results should be explored in the angiotensin system in future studies.

\section{Study limitations}

Since this was a cross-sectional study, future outcomes, such as new coronary events (myocardial infarction or stable/unstable angina), cannot be predicted. Additionally the sample could have been larger if routine DNA testing had been performed for every patient who required a coronary angiogram for their first coronary event, which might be possible in other institutions around the world.

\section{Potential clinical value}

It is anticipated that genetic information will become increasingly available for postmenopausal patients. It is important to identify examples in which the evidence is sufficiently robust and predictive to allow genetic information to guide clinical decisions and formulate preventive guidelines for CAD.

\section{Conclusion}

These data support an association between atherosclerosis and the renin-angiotensin system in a hypoestrogenic environment, which is intensified in overweight women. This association is dependent on the age at which the ischemic event is diagnosed.

\section{Author contributions}

Conception and design of the research: Lanz-Luces JR, Costa FA. Acquisition of data: Lanz-Luces JR, LanzSouquett JD. Analysis and interpretation of the data: Costa FA, Guzman L, Lanz-Luces JA, Costa LA. Statistical analysis: Costa FA, Lanz-Souquett JD. Obtaining financing: Lanz-Luces JR. Writing of the manuscript: 
Lanz-Luces JR, Guzman L, Lanz-Luces JA, Lanz-Souquett JD. Critical revision of the manuscript for intellectual content: Costa FA, Guzman L, Lanz-Luces JA, Costa LA.

\section{Potential Conflict of Interest}

No potential conflict of interest relevant to this article was reported.

\section{Sources of Funding}

This study was partially supported by grants from the Fundação de Amparo à Pesquisa do Estado de São Paulo
(FAPESP 01-00009-0) and was partially supported by a fellowship from the SBC/FUNCOR (Fundação do Coração) Fundo de Aperfeiçoamento e Pesquisa em Cardiologia.

\section{Study Association}

This article is part of post-hoc analysis of data from a late doctoral study (2005) submitted by José Ramón Lanz Luces, from Instituto do Coração (InCor), Escola de Medicina da Universidade de São Paulo, São Paulo, Brazil.

\section{References}

1. Akahoshi M, Soda M, Nakashima E, Tsuruta M, Ichimaru S, Seto S, et al. Effects of age at menopause on serum cholesterol, body mass index, and blood pressure. Atherosclerosis. 2001;156(1):157-63. doi: 10.1016/s00219150(00)00609-2

2. Campos H, Walsh BW, Judge H, Sacks FM. Effect of estrogen on very low density lipoprotein and low density lipoprotein subclass metabolism in postmenopausal women. J Clin Endocrinol Metab. 1997;82(12):3955-63. doi: 10.1210/jcem.82.12.4437.

3. Herrington DM, Howard TD, Hawkins GA, Reboussin DM, Xu J, Zheng SL, et al. Estrogen-receptor polymorphisms and effects of estrogen replacement on high-density lipoprotein cholesterol in women with coronary disease. $\mathrm{N}$ Engl J Med. 2002;346(13):967-74. doi: 10.1056/NEJMoa012952.

4. Walsh BW, Li H, Sacks FM. Effects of postmenopausal hormone replacement with oral and transdermal estrogen on high density lipoprotein metabolism. J Lipid Res. 1994;35(11):2083-93.

5. Rossouw JE, Anderson GL, Prentice RL, LaCroix AZ, Kooperberg C, Stefanick ML, et al. Risks and benefits of estrogen plus progestin in healthy postmenopausal women: principal results From the Women's Health Initiative randomized controlled trial.JAMA. 2002;288(3):321-33. doi: 10.1001/ jama.288.3.321.

6. Siemińska L, Cichoń-Lenart A, Kajdaniuk D, Kos-Kudła B, Marek B, Lenart $\mathrm{J}$, et al. Hormony płciowe i adipocytokiny u kobiet po menopauzie Sex hormones and adipocytokines in postmenopausal women. Pol Merkur Lekarski. 2006;20(120):727-30.

7. Cao H. Adipocytokines in obesity and metabolic disease. J Endocrinol. 2014;220(2):47-59. doi: 10.1530/JOE-13-0339.

8. Clasen R, Schupp M, Foryst-Ludwig A, Sprang C, Clemenz M, Krikov $\mathrm{M}$, et al. PPARgamma-activating angiotensin type-1 receptor blockers induce adiponectin. Hypertension. 2005;46(1):137-43. doi: 10.1161/01. HYP.0000168046.19884.6a.

9. Berg AH, Combs TP, Scherer PE. ACRP30/adiponectin: an adipokine regulating glucose and lipid metabolism. Trends Endocrinol Metab. 2002;13(2):84-9. doi: 10.1016/s1043-2760(01)00524-0.

10. Tzoulaki I, Murray GD, Lee AJ, Rumley A, Lowe GD, Fowkes FG. C-reactive protein, interleukin-6, and soluble adhesion molecules as predictors of progressive peripheral atherosclerosis in the general population: Edinburgh Artery Study. Circulation. 2005;112(7):976-83. doi: 10.1161/ CIRCULATIONAHA.104.513085

11. Guo F, Chen XL, Wang F, Liang X, Sun YX, Wang YJ. Role of angiotensin II type 1 receptor in angiotensin II-induced cytokine production in macrophages. J Interferon Cytokine Res. 2011;31(4):351-61. doi: 10.1089/jir.2010.0073.

12. Niu $\mathrm{T}, \mathrm{Chen} X, \mathrm{Xu} X$. Angiotensin converting enzyme gene insertion/deletion polymorphism and cardiovascular disease: therapeutic implications. Drugs. 2002;62(7):977-93. doi: 10.2165/00003495-200262070-00001.

13. Méthot J, Hamelin BA, Arsenault M, Bogaty P, Plante S, Poirier P. The ACE-DD genotype is associated with endothelial dysfunction in postmenopausal women. Menopause. 2006;13(6):959-66. doi: 10.1097/01. gme.0000243576.09065.93.

14. Amara A, Mrad M, Sayeh A, Lahideb D, Layouni S, Haggui A, et al. The Effect of ACE I/D Polymorphisms Alone and With Concomitant Risk Factors on Coronary Artery Disease. Clin Appl Thromb Hemost. 2018;24(1):157-163. doi: 10.1177/1076029616679505.

15. Gardemann A, Fink M, Stricker J, Nguyen QD, Humme J, Katz N, et al. ACE I/D gene polymorphism: presence of the ACE D allele increases the risk of coronary artery disease in younger individuals. Atherosclerosis. 1998;139(1):153-9. doi: 10.1016/s0021-9150(98)00040-9.

16. Pardhe BD, GhimireS, Shakya J, PathakS, ShakyaS, Bhetwal A, et al. Elevated Cardiovascular Risks among Postmenopausal Women: A Community Based Case Control Study from Nepal. Biochem Res Int. 2017;2017:3824903. doi: $10.1155 / 2017 / 3824903$

17. Collins KMT, Onwuegbuzie AJ, Jiao QG. A mixed methods investigation of mixed methods sampling designs in social and health science research. Journal of Mixed Methods Research 2007;1(3):267-294. doi: 10.1177/1558689807299526.

18. Lanz JR, Pereira AC, Lemos PA, Martinez E, Krieger JE. Angiotensinogen M235T polymorphism is associated with coronary artery disease severity. Clin Chim Acta. 2005;362(1-2):176-81. doi: 10.1016/j.cccn.2005.06.004.

19. Nallamothu BK, Spertus JA, Lansky AJ, Cohen DJ, Jones PG, Kureshi F, et al. Comparison of clinical interpretation with visual assessment and quantitative coronary angiography in patients undergoing percutaneous coronary intervention in contemporary practice: the Assessing Angiography (A2) project. Circulation. 2013;127(17):1793-800. doi: 10.1161/ CIRCULATIONAHA.113.001952

20. Morabia A, Costanza MC. International variability in ages at menarche, firs livebirth, and menopause. World Health Organization CollaborativeStudy of Neoplasia and Steroid Contraceptives. Am J Epidemiol. 1998;148(12):1195-205. doi: 10.1093/oxfordjournals.aje.a009609.

21. Nickenig G, Strehlow K, Wassmann S, Bäumer AT, Albory K, Sauer H, et al. Differential effects of estrogen and progesterone on $\mathrm{AT}(1)$ receptor gene expression in vascular smooth muscle cells. Circulation. 2000;102(15):1828-33. doi: 10.1161/01.cir.102.15.1828.

22. Liu HW, Iwai M, Takeda-Matsubara Y, Wu L, Li JM, Okumura M, et al. Effect of estrogen and AT1 receptor blocker on neointima formation. Hypertension 2002;40(4):451-7. doi: 10.1161/01.hyp.0000033466.05496.89.

23. Pirillo A, Norata GD, Catapano AL. LOX-1, OxLDL, and atherosclerosis Mediators Inflamm. 2013;2013:152786. doi: 10.1155/2013/152786.

24. Zhu Y, Xian X, Wang Z, Bi Y, Chen Q, Han X, et al. Research Progress on the Relationship between Atherosclerosis and Inflammation. Biomolecules. 2018;8(3):80. doi: 10.3390/biom8030080. 
25. Mao S, Huang S. A meta-analysis of the association between angiotensinconverting enzyme insertion/ deletion gene polymorphism and the risk of overweight/obesity. J Renin Angiotensin Aldosterone Syst. 2015;16(3):687-94. doi: 10.1177/1470320313501218.

26. Briguori C, Tobis J, Nishida T, Vaghetti M, Albiero R, Di Mario C, et al. Discrepancy between angiography and intravascular ultrasound when analysing small coronary arteries. Eur Heart J. 2002;23(3):247-54. doi: 10.1053/euhj.2001.2730.

27. Pepine CJ, Ferdinand KC, Shaw LJ, Light-McGroary KA, Shah RU, Gulati M, et al. Emergence of Nonobstructive Coronary Artery Disease:
A Woman's Problem and Need for Change in Definition on Angiography. J Am Coll Cardiol. 2015;66(17):1918-33. doi: 10.1016/j.jacc.2015.08.876.

28. Rumberger JA. Coronary Artery Disease: A Continuum, Not a Threshold. Mayo Clin Proc. 2017;92(3):323-326. doi: 10.1016/j.mayocp.2017.01.009.

29. Birnbaum Y, Fishbein MC, Luo H, Nishioka T, Siegel RJ. Regional remodeling of atherosclerotic arteries: a major determinant of clinical manifestations of disease. J Am Coll Cardiol. 1997;30(5):1149-64. doi: 10.1016/s0735-1097(97)00320-3.

30. Naito R, Miyauchi K. Coronary Artery Disease and Type 2 Diabetes Mellitus. Int Heart J. 2017;58(4):475-480. doi: 10.1536/ihj.17-191. 